\title{
A Summary of the Clinical Practice Guidelines for the Management of Patients with Peripheral Arterial Disease in Myanmar
}

\author{
Than Than Aye, ${ }^{1}$ Tint Swe Latt, ${ }^{2}$ Khin Mg Lwin, ${ }^{3}$ Win Win Kyaw, ${ }^{4}$ \\ Myint Soe Win, ${ }^{5}$ Moe Wint Aung, ${ }^{6}$ Ko Ko, ${ }^{1}$ Thein Myint, ${ }^{1}$ Yin Yin Win ${ }^{1}$ \\ ${ }^{1}$ Department of Medicine, North Okkalapa General Hospital, University of Medicine (2), Yangon, Myanmar \\ ${ }^{2}$ University of Medicine (2), Yangon, Myanmar \\ ${ }^{3}$ Department of Cardiac Surgery, University of Medicine (1), Yangon, Myanmar \\ ${ }^{4}$ Department of Cardiac Surgery, University of Medicine (2), Yangon, Myanmar \\ ${ }^{5}$ Department of Cardiology, University of Medicine (2), Yangon, Myanmar \\ ${ }^{6}$ Department of Medicine, Yangon General Hospital, University of Medicine (1), Yangon, Myanmar
}

\begin{abstract}
Peripheral artery disease (PAD) broadly encompasses vascular diseases caused primarily by atherosclerosis and thromboembolic pathophysiologic processes that alter the normal structure and function of the aorta, its visceral arterial branches, and the arteries of the lower extremity. The aims of the Myanmar clinical practice guidelines for the management of patients with PAD are to assist physicians in selecting the best management strategies for an individual patient with peripheral artery disease with main focus on lower extremity artery disease (LEAD) due to atherosclerosis, to help the physician to make decisions in their daily practice, and to aid in appropriate referrals to specialists. Early detection and treatment guidelines for the treatment of PAD are important to reduce the morbidity and mortality of patients with vascular problems in Myanmar.
\end{abstract}

Key words: peripheral arterial disease, clinical practice guidelines, Myanmar

\section{INTRODUCTION}

Cardiovascular diseases (CVDs) are the leading cause of death and disability worldwide. Coronary artery disease (CAD) is the main cause of death, but stroke, renal failure, and severe ischaemia of the lower extremities also contribute to a significant burdens. There are studies which shown evidences of a substantial percentage of patients with chronic CAD have associated with cerebrovascular disease, lower extremity artery disease (LEAD), or both. ${ }^{1}$

Therefore, the patients with heart disease are required to be assessed for vascular problems in other territories, both symptomatic and asymptomatic, that may affect their prognosis and treatment strategy. The patients with PAD will also probably die from CAD. ${ }^{2}$

The term peripheral artery disease (PAD) broadly encompass the vascular diseases caused primarily by atherosclerosis and thromboembolic pathophysiologic processes that alter the normal structure and function of the aorta, its visceral arterial branches, and the arteries of the lower extremity. PAD is the preferred clinical term and should be used to denote stenotic, occlusive and aneurysmal diseases of the aorta and its branch arteries, exclusive of the coronary arteries. ${ }^{3}$

PAD has a significant impact of on the incidence of major amputations and its consequent poor prognosis as patients

e-ISSN 2308-118X

Printed in the Philippines

Copyright (C) 2013 by the JAFES

Received October 11, 2013. Accepted October 14, 2013. are more at risk for repeated amputations of remaining limbs and even death. ${ }^{4}$

The aims of this guideline is for assisting physicians in selecting the best management strategies for an individual patient with peripheral artery disease with main focus on lower extremity artery disease (LEAD) due to atherosclerosis. It will help the physicians to make decisions in their daily practice and aid in appropriate referrals to specialists. However, the final decisions must be made by the responsible physician(s).

\section{Summary of methodology of guideline development}

In the development of this guideline, the following issues are taken into consideration, in that the recommendations must be:

- Evidence-based

- Adapted to the local setting

- Considers patient's values in decision making

- $\quad$ Ensure equity

Members of this Task Force were selected to represent professionals involved with the care of patients with peripheral vascular disease. These included general physicians (internists), endocrinologists (including pediatric endocrinologists), cardiac physicians, cardiovascular surgeons, family physicians.

A review of the literatures and evidences regarding the diagnostic and therapeutic procedures was performed.

Corresponding author: Prof. Tint Swe Latt

President, Myanmar Society of Endocrinology and Metabolism

University of Medicine 2, Yangon, Myanmar

Tel. No.: +959-5167332

E-mail:proftsl@gmail.com 
The level of evidence and the strength of recommendation of particular treatment options were weighed and graded according to standard scales as mentioned below. It was published after appropriate revisions and approval by all the experts involved in the Task Force.

\section{Summary of Recommendations}

\begin{tabular}{|c|c|c|}
\hline $\begin{array}{c}\text { Classes of } \\
\text { recommendations }\end{array}$ & Definition & $\begin{array}{c}\text { Suggested } \\
\text { wording to use }\end{array}$ \\
\hline Class I & $\begin{array}{l}\text { Evidence and/or general } \\
\text { agreement that a given } \\
\text { treatment or procedure is } \\
\text { beneficial, useful, effective. }\end{array}$ & $\begin{array}{l}\text { Is } \\
\text { recommended/ } \\
\text { is indicated }\end{array}$ \\
\hline Class II & $\begin{array}{l}\text { Conflicting evidence and/or } \\
\text { a divergence of opinion } \\
\text { about the } \\
\text { usefulness/efficacy of the } \\
\text { given treatment or } \\
\text { procedure. }\end{array}$ & \\
\hline Class Ila & $\begin{array}{l}\text { Weight of evidence/opinion } \\
\text { is in favour of } \\
\text { usefulness/efficacy. }\end{array}$ & $\begin{array}{l}\text { Should be } \\
\text { considered }\end{array}$ \\
\hline Class IIb & $\begin{array}{l}\text { Usefulness/efficacy is less } \\
\text { well established by } \\
\text { evidence/opinion }\end{array}$ & $\begin{array}{l}\text { May be } \\
\text { considered }\end{array}$ \\
\hline Class III & $\begin{array}{l}\text { Evidence or general } \\
\text { agreement that the given } \\
\text { treatment or procedure is } \\
\text { not useful/effective, and in } \\
\text { some cases may be harmful. }\end{array}$ & $\begin{array}{l}\text { Is not } \\
\text { recommended }\end{array}$ \\
\hline
\end{tabular}

\section{Table 2. Levels of evidence}

\begin{tabular}{cl}
\hline Level of Evidence A & $\begin{array}{l}\text { Data derived from multiple randomized } \\
\text { clinical trials or meta-analyses. }\end{array}$ \\
Level of Evidence B & $\begin{array}{l}\text { Data derived from a single randomized } \\
\text { clinical trial or large non-randomized studies. }\end{array}$ \\
Level ofEvidence C & $\begin{array}{l}\text { Consensus of opinion of the experts and/ or } \\
\text { small studies, retrospective studies, registries. }\end{array}$ \\
\hline
\end{tabular}

\section{Epidemiology}

Prevalence of PAD in the general population of different parts of the world including Asian countries ranges from $4 \%$ to $20 \%$. $^{6-10}$ In Myanmar, there is no overall prevalence data covering the whole population. However, data from the cardiac surgery unit of Yangon General Hospital (2010 to 2012 ) indicated that about $10 \%$ of total admissions was due to LEAD, of which approximately $75 \%$ had undergone intervention procedures such as embolectomy, bypass graft and sympathectomy. Hospital-based study of general surgical ward in Yangon General Hospital indicated that $7 \%$ of total admission was due to PAD and $10 \%$ of PAD cases ended in amputation.

The frequency of LEAD is age related: uncommon before 50 years, rising steeply at older age. ${ }^{11}$ Although more common in males, there is equilibration between sexes with increasing age.

\section{Risk factors}

Risk factors for PAD are similar to the typical risk factors for atherosclerotic disease. These include the traditional risk factors: smoking, dyslipidaemia, diabetes mellitus, and hypertension. Smoking would appear to be a stronger risk factor for LEAD than for CAD.

Diabetes mellitus is an important risk for the development of LEAD. ${ }^{12}$ Patients with diabetes have an increased prevalence, reported to be as high as $30 \%$ in some studies. ${ }^{13}$ In those with intermittent claudication, the strength of the association with diabetes may be comparable with that for coronary heart disease. It appears that the duration and severity of diabetes affect the level of risk. ${ }^{12,14}$

Most epidemiological studies show an association between hypertension and the presence of LEAD. Hypertension was associated with an increased relative risk of 2.8 for LEAD $^{15}$ and a low ABI $(<0.90)$ was associated with both increased systolic and diastolic blood pressure. ${ }^{16}$

Most of the studies have found that high total cholesterol and low high-density lipoprotein (HDL) cholesterol are independently related to an increased risk of LEAD. The ratio of total/HDL cholesterol was the lipid measure most strongly related to disease. ${ }^{17}$

\section{Diagnostic approach of lower extremity artery disease}

\subsection{Clinical presentation}

The Fontaine classification ${ }^{18}$ is recommended for the categorization of LEAD because this classification is simple and more applicable for clinical decision in diagnosis and management of LEAD patients in Myanmar.

Table 3. Clinical staging of LEAD

\begin{tabular}{cc}
\hline & \multicolumn{1}{c}{ Fontaine Classification } \\
\hline Stage & Symptom \\
I & Asymptomatic \\
II & Intermittent claudication \\
IV & Ischaemic rest pain \\
\hline
\end{tabular}

They may be asymptomatic or typically present with intermittent claudication, characterized by pain in the calves, increasing with walking: the pain typically disappears quickly at rest.

The Edinburgh Claudication Questionnaire ${ }^{19}$ is recommended as a screening method of intermittent claudication.

In physical examination, the feet must be inspected, and the colour, temperature, and integrity of the skin, and the presence of ulcerations recorded. Additionally, calf hair loss and skin changes should also be noted.

Pulse palpation should be done systematically. Palpation of the femoral, popliteal, dorsalis pedis, and posterior tibial sites must be done. Auscultation of bruits over the 
femoral artery at the groin and more distally is also suggestive. Examination of other arteries such as radial, carotid, abdominal aorta should also be done.

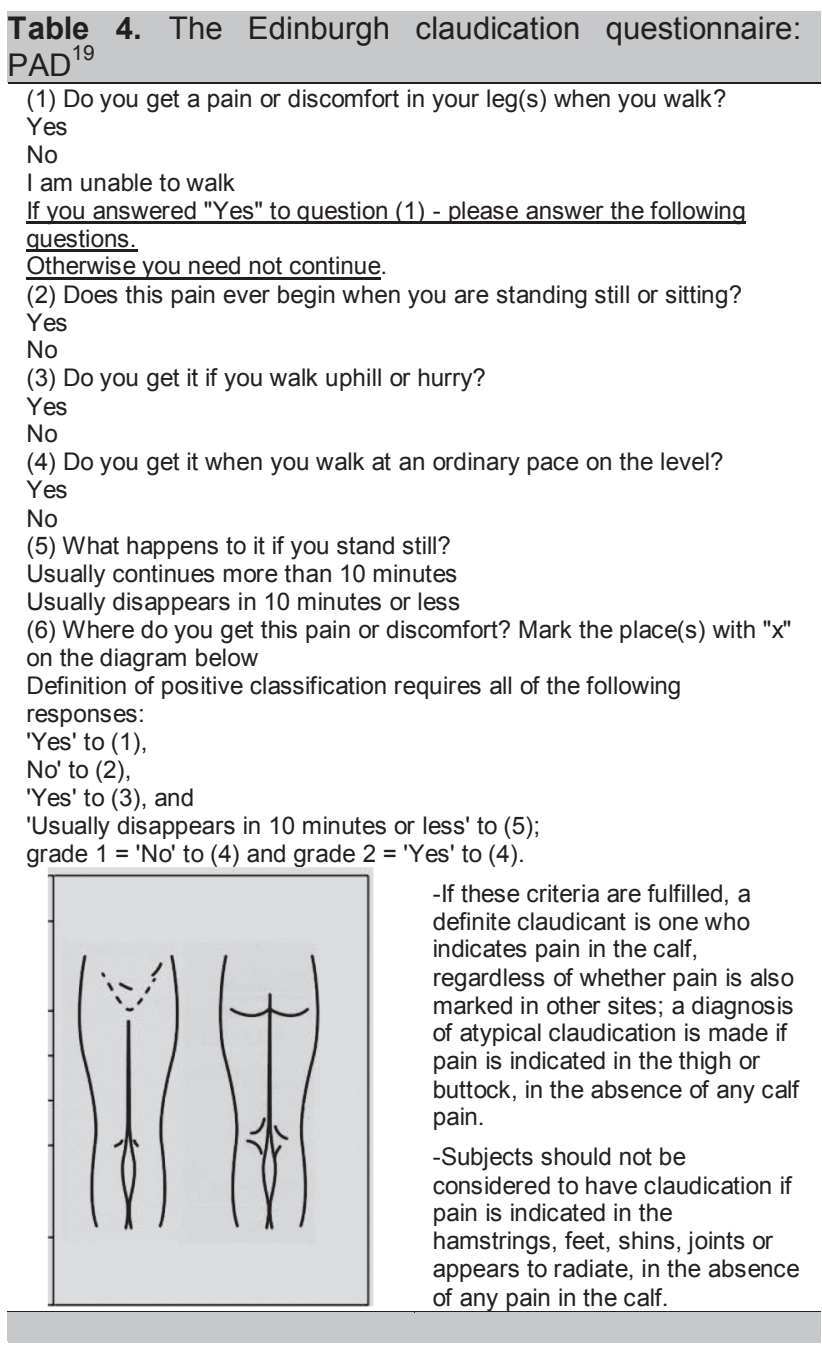

\subsection{Diagnostic tests}

\subsubsection{Ankle-brachial index}

The clinical diagnosis can be strongly improved by measuring the Ankle-Brachial index (ABI). This is the ratio of the ankle to brachial systolic pressure and can be measured easily using a sphygmomanometer and handheld Doppler device. Measurement of ankle brachial pressure index should be taken by properly trained practitioners.

In healthy persons, the $\mathrm{ABI}$ is 1.0.ABI of $<0.90 \mathrm{had}$ a positive predictive value of $\geq 95 \%$; an $\mathrm{ABI}>1.10$ had a negative predictive value of $\geq 99 \% .^{20}$ In practice, an ABI of $<0.9$ is considered to be abnormal. The ABI of patients with intermittent claudication typically lies between 0.5 and 0.9. Critical limb ischaemia (Fontaine stage III or IV) is generally associated with an $\mathrm{ABI}$ of $<0.5$. For values $>1.5$, the vessels are likely to be incompressible, and the result can be seen in calcified arteries, in the case of diabetes, ESRD, and in the very elderly.
Although highly sensitive and specific for PAD, a normal $\mathrm{ABI}$ at rest, in combination with classic symptoms, will necessitate referral for an ABI measurement after exercise and/or imaging to confirm or refute a possible diagnosis.

\section{Technique of $A B I$ measurement ${ }^{5}$}

A 10-12 cm sphygmomanometer cuff placed just above the ankle and a (handheld) Doppler instrument (5-10 $\mathrm{MHz}$ ) to measure the pressure of the posterior and anterior tibial arteries of each foot are required. Usually the highest ankle systolic pressure is divided by the highest brachial systolic pressure, resulting in an ABI per leg. Recently some papers reported higher sensitivity to detect LEAD if the ABI numerator is the lowest pressure in the arteries of both ankles. ${ }^{21}$
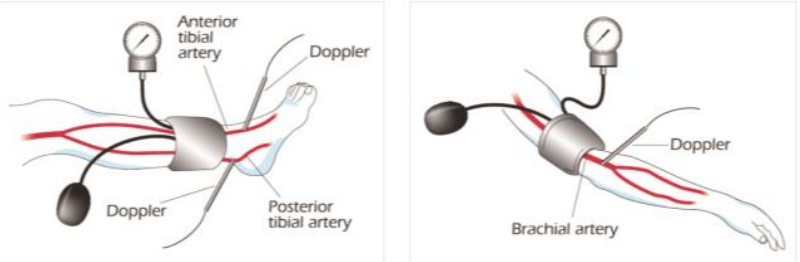

Figure 1. Measurement of the ankle-brachial index (ABI), calculated by dividing the ankle systolic blood pressure by the arm systolic blood pressure

\section{Exercise ankle brachial pressure index}

The ABI before and after exercise is helpful in evaluating patients with classic symptoms and a normal or borderline resting $\mathrm{ABI}$.

The patient is asked to walk (commonly on a treadmill at $3.2 \mathrm{~km} / \mathrm{h}$ at a $10-20 \%$ slope) until claudication pain occurs and impedes walking. An ABI drop after exercise indicates LEAD. ${ }^{22}$

\section{Recommendations for $A B I$ measurement}

Measurement of the ABI is indicated as a first-line noninvasive test for screening and diagnosis of LEAD. (Class I, Level B) ${ }^{23}$

\subsubsection{Ultrasound methods}

\section{Duplex Ultrasonography (DUS)}

DUS provides extensive information on both arterial anatomy and blood flow. DUS sensitivity to detect $>50 \%$ diameter angiographic stenosis is $85-90 \%$, with a specificity $>95 \% .^{24-26}$

Combined with the ABI, DUS provides all the information necessary for management decisions in the majority of patients with LEAD.

DUS is also highly useful for the follow-up after angioplasty or to monitor bypass grafts..$^{27,28}$ 


\section{Recommendations for DUS}

Non-invasive assessment method, DUS is indicated as first-line method to confirm and localize LEAD lesions. (Class I, Level B) 29,30

\subsubsection{Angiography}

\section{Computed tomography angiography}

The use of computed tomography angiography (CTA) is not recommended for screening purposes.

CTA can detect aortoiliac stenoses $>50 \%$ (sensitivity $96 \%$ and specificity 98\%), ${ }^{31}$ stenoses of femoropopliteal region (sensitivity $97 \%$ and specificity $94 \%$ ) and the below-knee arteries (sensitivity 95\%, specificity 91\%) respectively. ${ }^{31}$

The great advantage of CTA remains the visualization of calcifications, clips, stents and bypasses.

\section{Magnetic resonance angiography}

MRA can non-invasively visualize the lower limb arteries even in the most distal parts. MRA has an excellent sensitivity (93-100\%) and specificity (93-100\%). ${ }^{25,32-36}$

\section{Recommendation for angiography}

DUS and/or CTA and/or MRA are indicated to localize LEAD lesions and consider revascularization options. (Class I, Level A) 25,26,27,28,31-36,37,38

\section{Management}

The management of peripheral arterial disease should include:

(1) General management

- Lifestyle modification

- Cardiovascular risk reduction

(2) Specific management of LEAD

- Conservative treatment

- Endovascular treatment or surgery

\subsection{General management (Treatment of both asymptomatic and symptomatic LEAD)}

\subsubsection{Lifestyle modification}

\section{Recommendation regarding nutrition}

A healthy diet is recommended as being the cornerstone of CVD prevention. (Class I, Level B) ${ }^{39-45}$

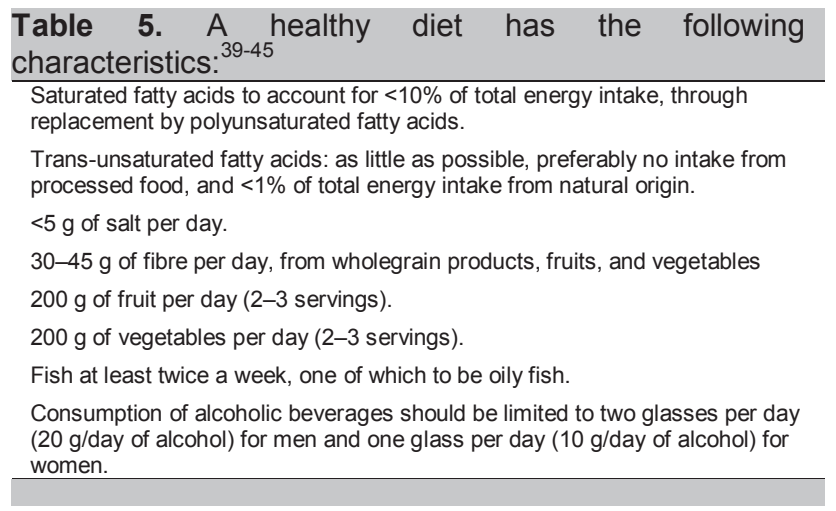

\section{Recommendations regarding physical activity}

Patients with previous CVD should undergo moderate tovigorous intensity aerobic exercise training $\geq 3$ times a week and 30 min per session. Sedentary patients should be strongly encouraged to start light-intensity exercise programmes after adequate exercise-related risk stratification. (Class I, Level A) ${ }^{46,47}$

\section{Recommendation regarding body weight}

Both overweight and obesity are associated with a risk of death in CVD. There is a positive linear association of BMI with all-cause mortality. All-cause mortality is lowest with a BMI of $20-25 \mathrm{~kg} / \mathrm{m} 2$. $^{48-50}$

Weight reduction in overweight and obese people is recommended as this is associated with favourable effects on blood pressure and dyslipidaemia, which may lead to less CVD. (Class I, Level A) ${ }^{48-50}$

\subsubsection{Cardiovascular risk reduction}

\section{Smoking cessation}

Smokers should be advised to quit smoking.

Nicotine replacement therapy and/or bupropion or varenicline can be used to facilitate smoking cessation ${ }^{51}$

\section{Lipid lowering drugs}

Statins reduce the risk of mortality, cardiovascular events and stroke in patients with PAD with and without CAD.

It also has preliminary positive effects on PAD and increase in maximal walking distance of $163 \mathrm{~m} .{ }^{52}$

\section{Antihypertensive drugs}

Treatment with angiotensin-converting enzyme (ACE) inhibitors or Angiotensin Receptor Blockers has shown a beneficial effect beyond a blood pressure decrease in highrisk groups. Beta -blockers are not contraindicated in patients with LEAD. ${ }^{53,54}$

\section{Antiplatelet and antithrombotic drugs}

Low-dose aspirin (75-150 mg daily) is as effective as higher daily doses. ${ }^{55}$ Clopidogrel is an alternative to aspirin.$^{56}$

Dual antiplatelet therapy should not be recommended in patients with LEAD due to an increased bleeding risk. 57,58

\section{Recommendation for general management}

All patients with PAD who smoke should be advised to stop smoking. (Class I, Level B) ${ }^{59}$

All patients with PAD should have their LDL cholesterol lowered to $<2.5 \mathrm{mmol} / \mathrm{L}$ (100 mg/dL), and optimally to $<1.8$ $\mathrm{mmol} / \mathrm{L}(70 \mathrm{mg} / \mathrm{dL})$, or $\geq 50 \%$ when the target level cannot be reached. (Class I, Level C)

All patients with PAD should have their blood pressure controlled to $\leq 140 / 90 \mathrm{mmHg}$.(Class I, Level A) ${ }^{60}$

B-Blockers are not contraindicated in patients with LEAD, and should be considered in the case of concomitant 
coronary artery disease and/or heart failure. (Class IIa, Level B) ${ }^{61,62}$

Antiplatelet therapy is recommended in patients with symptomatic PAD. (Class I, Level C) ${ }^{55}$

In patients with PAD and diabetes, the HbA1c level should be kept at $\leq 6.5 \%$. (Class I, Level C)

In patients with PAD, a multidisciplinary approach is recommended to establish a management strategy. (Class I, Level C)

\subsection{Specific management of LEAD (treatment of symptomatic LEAD-Intermittent Claudication)}

\subsubsection{Conservative treatment}

The aim of conservative treatment in patients with intermittent claudication is to improve symptoms, i.e., increase walking distance and comfort. Two strategies are currently used:

(i) Exercise therapy

(ii) Pharmacotherapy

\subsubsection{Exercise Therapy}

Training therapy is effective in improving symptoms and increasing exercise capacity. The training programme lasts for 3 months, with three sessions per week. Daily walking, or repeated series of heel raising or knee bending are realistic possibilities. ${ }^{63}$ Patients with Fontaine class IV should not be submitted to regular exercise training.

\subsubsection{Pharmacotherapy}

Pharmacotherapy can be used to increase walking distance in patients with intermittent claudication.

\section{Cilostazol (100 mg BD)}

Cilostazol is a phosphodiesterase-3 inhibitor. The dose of cilostazol $50 \mathrm{mg} /$ day can increase the maximal walking distance $36 \mathrm{~m}$ on average and almost twice $(70 \mathrm{~m})$ with the $100 \mathrm{mg}$ dose. ${ }^{52}$ Improvement in quality of life is also reported in claudicants. ${ }^{64}$

\section{Pentoxifylline (400 mg tds)}

Pentoxifylline is a phosphodiesterase inhibitor and a significant increase in maximal walking distance was found with pentoxifylline $(+59 \mathrm{~m}) .^{52}$

\subsubsection{Revascularization}

To select the most appropriate revascularization procedure, the main issues to be considered are the anatomical suitability (Lesion classification according to the Trans Atlantic Inter-Society Consensus TASC), comorbidities, local availability and expertise and the patient's preference.

\subsubsection{Endovascular treatment of lower extremity artery disease}

Endovascular interventions are not indicated as prophylactic therapy in an asymptomatic patient. In Myanmar, endovascular intervention by stent is rarely done.
The major drawback of endovascular interventionscompared with surgery -is the lower long-term patency.

\subsubsection{Surgery}

Bypass surgery presents the most common surgical approach for diffuse occlusive disease. Different graft materials can be applied. Autologous vein or artery grafts are the best options. If it is not always available or applicable, prosthetic grafts are considered.

Primary amputation may best be served for the patients with extensive necrosis or infectious gangrene and those who are non-ambulatory.

Amputation remains the last surgical step to solve irreversible limb ischaemia.

\section{Recommendation for surgical revascularization}

When surgery is considered to revascularize infrailiac lesions, the autologous saphenous vein is the bypass graft of choice.( Class I, Level A) ${ }^{65,66}$

Recommendations for antiplatelet and anticoagulant therapy after revascularization

Antiplatelet therapy with aspirin is recommended in all patients with angioplasty for LEAD to reduce the risk of systemic vascular events. (Class I, Level C)

Dual antiplatelet therapy with aspirin and a thienopyridine for at least one month is recommended after infrainguinal bare-metal-stent implantation. (Class I, Level C)

Antiplatelet treatment with aspirin or a combination of aspirin and dipyridamole is recommended after infrainguinal bypass surgery. (Class I, Level A) ${ }^{67}$

Antithrombotic treatment with vitamin $\mathrm{K}$ antagonists may be considered after autogenous vein infrainguinal bypass. (Class Ilb, Level B) ${ }^{68}$

Dual antiplatelet therapy combining aspirin and clopidogrel may be considered in the case of below-knee bypass with a prosthetic graft. (Class IIb, Level B) ${ }^{69}$

\section{CONCLUSION}

Since the patients with PAD will also probably die from CAD, screening and evaluation of comorbidities may affect their treatment outcome.

On the other hand, all the patients with CAD should be assessed for vascular problems in other territories.

The combination of early defection and clear guideline for the treatment of PAD will definitely help to reduce the morbidity and mortality of patients with vascular problems. 


\section{Algorithm (1)}

Diagnosis and Treatment of Asymptomatic Peripheral Arterial Disease and Atypical Leg Pain (Adapted from the 2011 ACCF/AHA PAD guideline and modified according to local situation $)^{3}$

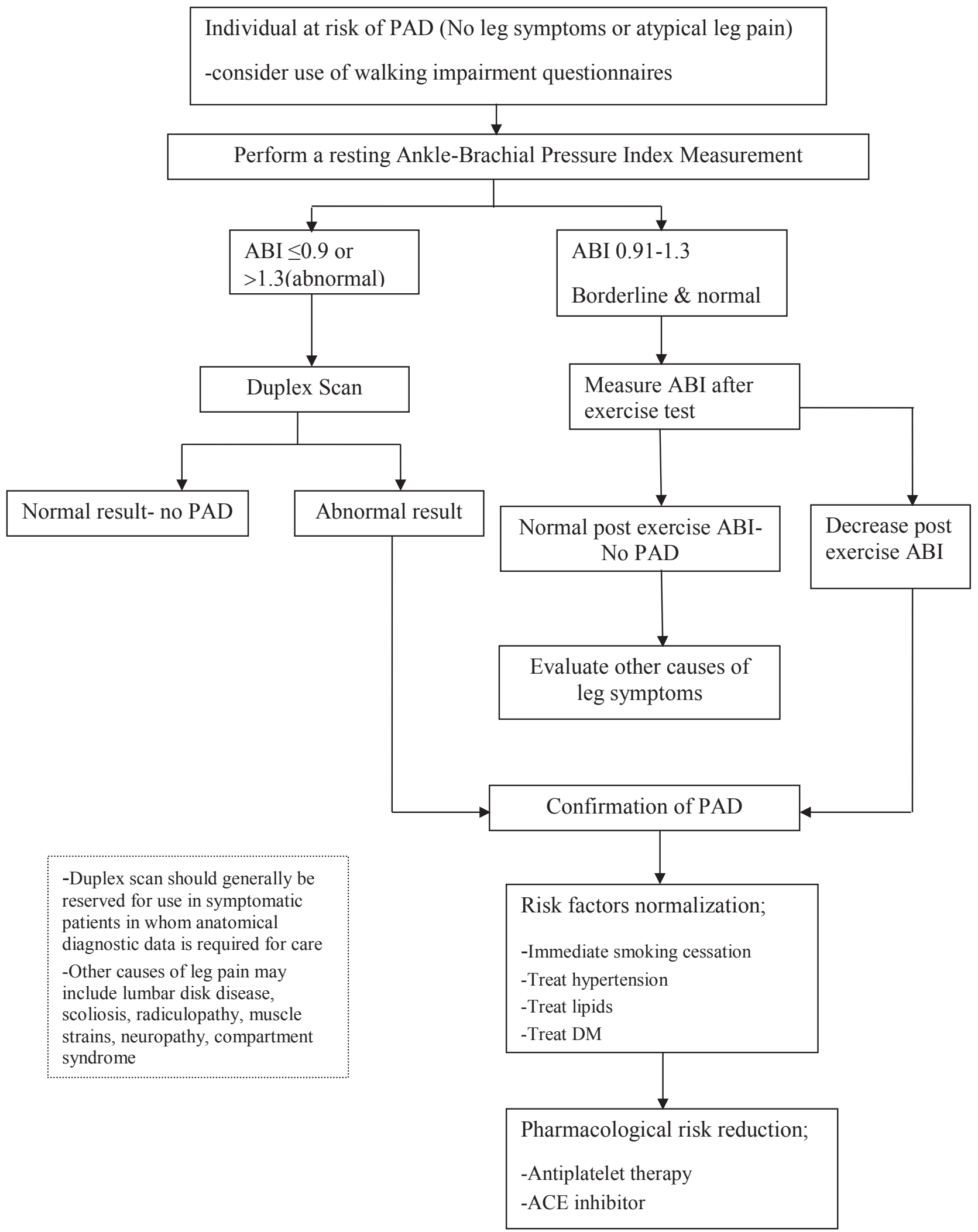




\section{Algorithm (2)}

General Management of Intermittent Claudication (Adapted from the 2011 ACCF/AHA PAD guideline and modified according to local situation $)^{3}$

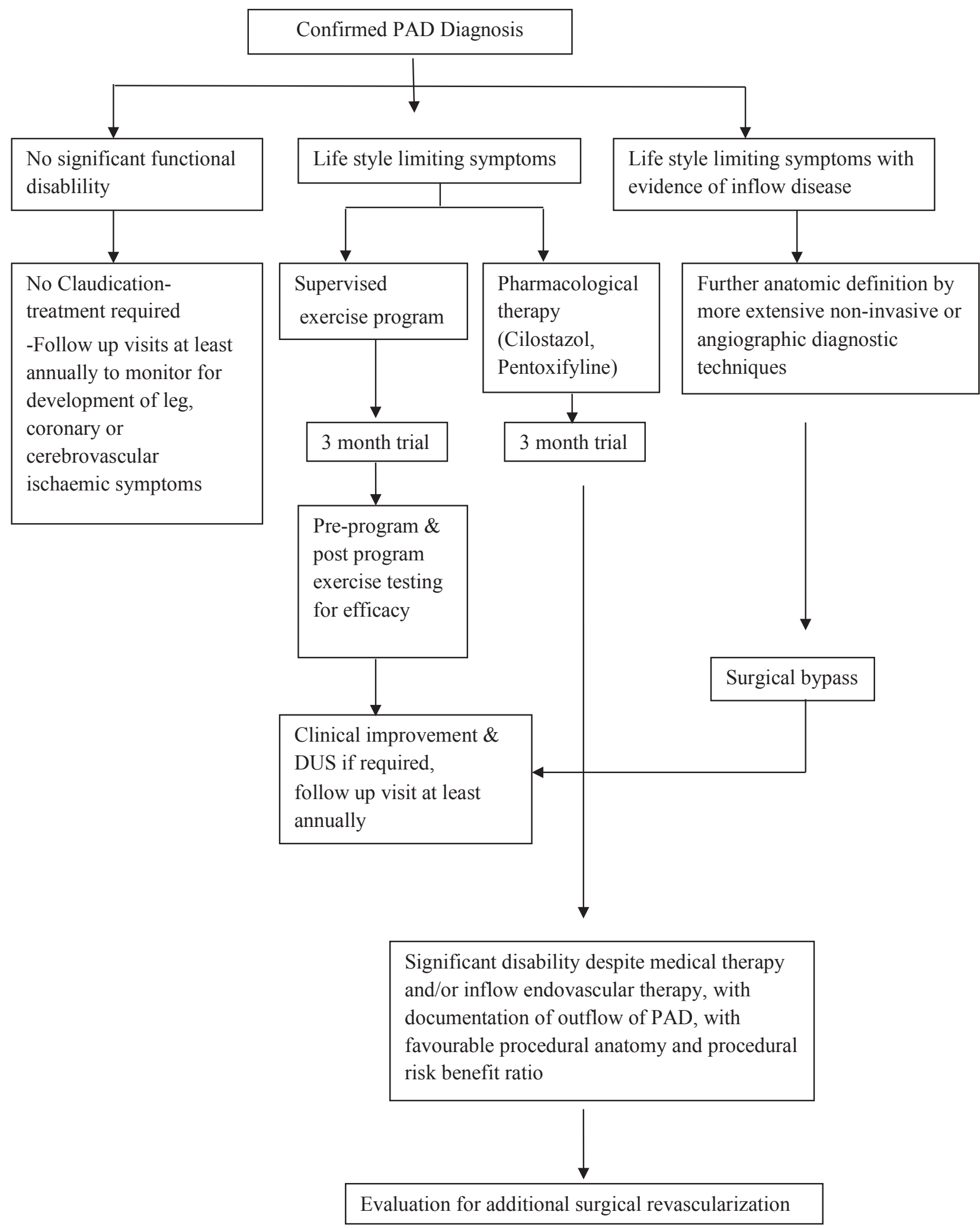




\section{Algorithm (3)}

Management of acute limb ischaemia (Adapted from the 2011 ACCF/AHA PAD guideline and modified according to local situation $)^{3}$

\section{(A) Diagnosis}

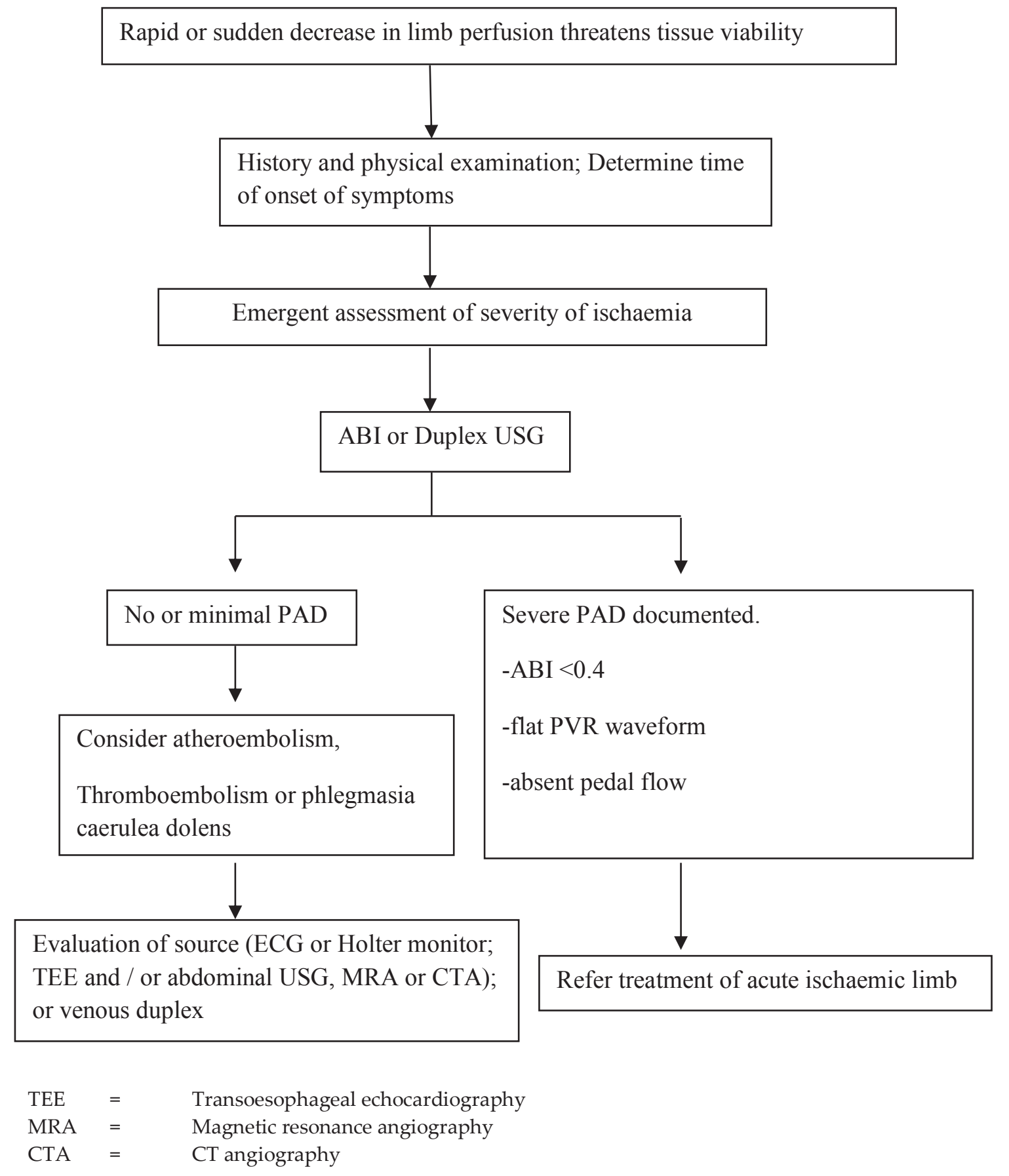


(B) Treatment of Acute Limb Ischaemia (Adapted from the 2011 ACCF/AHA PAD guideline and modified according to local situation) ${ }^{3}$

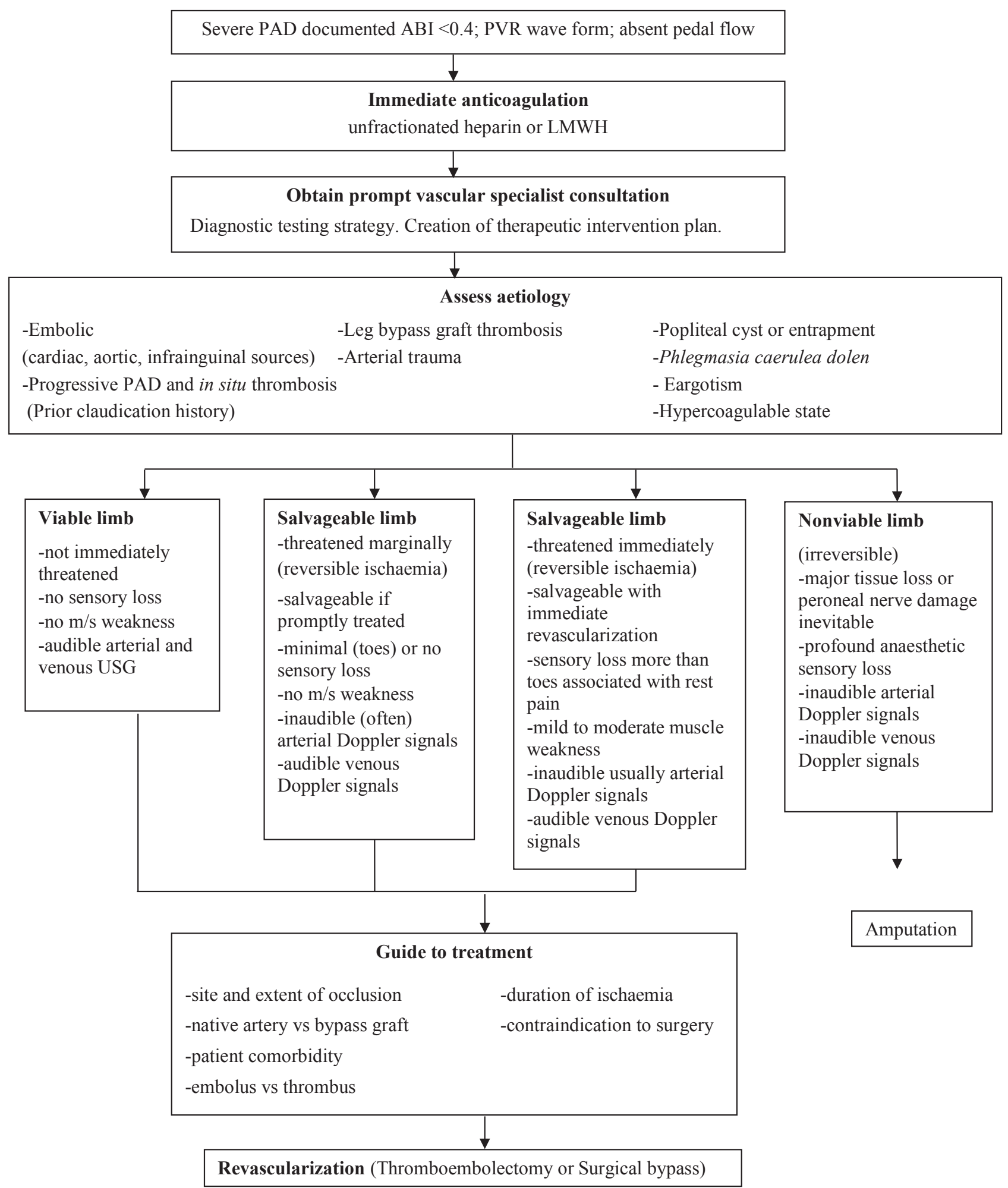




\section{Algorithm (4)}

Diagnosis and Treatment of Critical Limb Ischaemia (Adapted from the 2011 ACCF/AHA PAD guideline and modified according to local situation $)^{3}$

Chronic symptoms: ischaemic pain, gangrene, non healing wound

Ischaemic aetiology must be established promptly: by examination $\&$ objective vascular studies

Implication: Impending limb loss

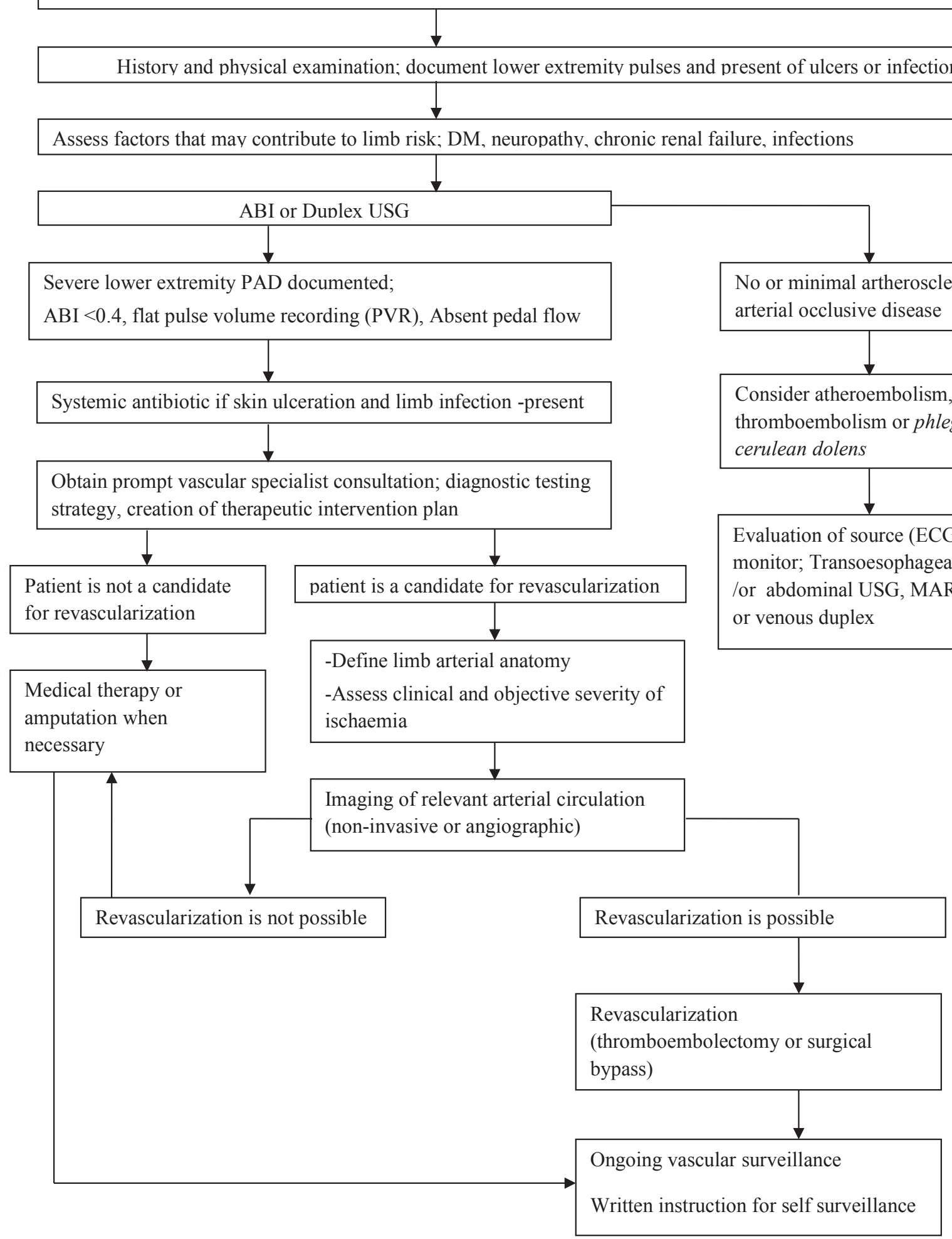




\section{References}

1. Steg PG, Bhatt DL, Wilson PW, D'Agostino R Sr, Ohman EM, Rother $\mathrm{J}$, et al. One-year cardiovascular event rates in out patients with atherothrombosis. JAMA 2007;297:1197-1206

2. Criqui $\mathrm{MH}$, Langer RD, Fronek A, Feigelson HS, Klauber MR, McCann TJ, et al. Mortality over a period of 10 years in patients with peripheral arterial disease. N Engl J Med 1992;326:381-386.

3. The 2011 ACCF/AHA Focused update of the guideline for the management of patients with peripheral artery disease J Am Coll Cardiol 2011;58:2020-2045 and the 2005 ACC/AHA guidelines for the management of patients with peripheral artery disease (lower extremity, renal, mesenteric, and abdominal aortic) J Am Coll Cardiol 2006;47:1239-312.

4. Norgren L, Hiatt WR, Dormandy JA, Nehler MR, Harris KA, Fowkes FGR. Inter-Society consensus for the management of peripheral arterial disease (TASC II).JVascSurg 2007;45:S5-S67.

5. ESC Guidelines on the Diagnosis and Treatment of Peripheral artery diseases. European Heart J 2011;32:2851-2906.

6. Tsai, AW, Folsom, AR, Rosamond, WD, Jones, DW . Ankle-brachial index and 7-year ischemic stroke incidence: the ARIC study. Stroke 2001; 32: 1721-24

7. Fowkes, FG, Housley, E, Cawood, EH, Macintyre, CC,Ruckley, CV, Prescott, RJ . Edinburgh Artery Study: prevalence of asymptomatic and symptomatic peripheral arterial disease in the general population. Int J Epidemiol 1991; 20: 384-92.

8. Meijer WT, Hoes AW, Rutgers D, Bots ML, Hofman A, Grobbee DE. Peripheral arterial disease in the elderly. The Rotterdam Study Arterioscler Thromb Vasc Biol. 1998; 185-192.

9. Allison, MA, Criqui, MH, McClelland, RL. The effect of novel cardiovascular risk factors on the ethnic specific odds for peripheral arterial disease in the Multi- Ethnic Study of Atherosclerosis (MESA) J Am Coll Cardiol 2006;48: 1190-97.

10. Selvin, E, Erlinger, TP . Prevalence of and risk factors for peripheral arterial disease in the United States: Results from the National Health and Nutrition Examination Survey,1999-2000. Circulation 2004;110 738-43.

11. Kroger K, Stang A, Kondratieva J, Moebus S, Beck E, Schmermund A,et al. Prevalence of peripheral arterial disease-results of the Heinz Nixdorf recall study. Eur J Epidemiol 2006;21:279-285.

12. Criqui $\mathrm{MH}$. Peripheral arterial disease epidemiological aspects.Vasc Med 2001;6:3-7.

13. Hirsch, AT, Criqui, MH, Treat-Jacobson, D. Peripheral arterial disease detection, awareness, and treatment in primary care. JAMA 2001;286 1317-24

14. Fowkes FG, Housley E, Riemersma RA, Macintyre CC, Cawood EH, Prescott RJ, Ruckley CV. Smoking, lipids, glucose intolerance, and blood pressure as risk factors for peripheral atherosclerosis compared with ischemic heart disease in the Edinburgh Artery Study. Am J Epidemiol 1992;135:331-340.

15. Stoffers HE, Rinkens PE, Kester AD, Kaiser V, Knottnerus JA. The prevalence of asymptomatic and unrecognized peripheral arterial occlusive disease. Int J Epidemiol 1996;25:282-290.

16. Meijer WT, Hoes AW, Rutgers D, Bots ML, Hofman A,Grobbee DE Peripheral arterial disease in the elderly: the Rotterdam Study. ArteriosclerThrombVascBiol 1998;18:185-192.

17. Ridker PM, Stampfer MJ, Rifai N. Novel risk factors for systemic atherosclerosis: a comparison of C-reactive protein, fibrinogen, homocysteine, lipoprotein(a), and standard cholesterol screening as predictors of peripheral arterial disease. JAMA 2001;285:2481 2485.

18. Dormandy JA, Rutherford RB, for the TASC Working Group. TransAtlanticInter Society Consensus (TASC). Management of peripheral arterial disease (PAD). J Vas Surg 2000;31:S1-S296.

19. Leng GC, Fowkes FG. The Edinburgh Claudication Questionnaire: an improved version of the $\mathrm{WHO} /$ Rose Questionnaire for use in epidemiological surveys. J ClinEpidemiol 1992;45:1101-1109.

20. Stoffers HE, Kester AD, Kaiser V, Rinkens PE, Kitslaar PJ, Knottnerus JA. The diagnostic value of the measurement of the ankle-brachial systolic pressure index in primary health care. J ClinEpidemiol 1996;49:1401-1405.

21. Schroder F, Diehm N, Kareem S, Ames M, Pira A, Zwettler U, LawallH,Diehm C. A modified calculation of ankle-brachial pressure index is far more sensitive in the detection of peripheral arterial disease. J VascSurg 2006;44:531-536
22. Stein R, Hriljac I, Halperin JL, Gustavson SM, Teodorescu V, Olin JW Limitation of the resting ankle-brachial index in symptomatic patients with peripheral arterial disease.Vasc Med 2006;11:29-33.

23. Lijmer JG, Hunink MG, van den Dungen JJ, Loonstra J, Smit AJ. ROC analysis of noninvasive tests for peripheral arterial disease. Ultrasound Med Biol 1996;22:391-398.

24. Koelemay MJ, den Hartog D, Prins MH, Kromhout JG, Legemate DA, Jacobs MJ. Diagnosis of arterial disease of the lower extremities with duplex ultrasonography. Br J Surg 1996;83:404-409.

25. Visser K, Hunink MG. Peripheral arterial disease: gadoliniumenhanced MRangiography versus color-guided duplex US-a metaanalysis. Radiology 2000;216:67-77.

26. Collins R, Cranny G, Burch J, Aguiar-Ibanez R, Craig D, Wright K,et al. A systematic review of duplex ultrasound, magnetic resonance angiography and computed tomography angiography for the diagnosis and assessment of symptomatic, lower limb peripheral arterial disease. Health Technol Assess 2007;11:iii-iv, xi-xiii, 1-184.

27. Bandyk DF, Chauvapun JP. Duplex ultrasound surveillance can be worth while after arterial intervention. Perspect Vasc Surg Endovasc Ther 2007;19:354-359; discussion 360-351.

28. Ferris BL, Mills JL Sr, Hughes JD, Durrani T, Knox R. Is early postoperative duplex scan surveillance of leg bypass grafts clinically important? J VascSurg 2003;37:495-500.

29. Barnes RW. Noninvasive diagnostic assessment of peripheral vascular disease. Circulation 1991;83:I20-I27.

30. Clement DL, Van Maele GO, De Pue NY. Critical evaluation of venous occlusion plethysmography in the diagnosis of occlusive arterial diseases in the lowerlimbs. Int Angiol 1985;4:69-74.

31. Met R, Bipat S, Legemate DA, Reekers JA, Koelemay MJ. Diagnostic performance of computed tomography angiography in peripheral arterial disease: A systematic review and meta-analysis. JAMA 2009;301:415-424.

32. Poon E, Yucel EK, Pagan-Marin H, Kayne H. Iliac artery stenosis measurements:Comparison of two-dimensional time-of-flight and three-dimensional dynamic gadolinium-enhanced MR angiography. AJR Am J Roentgenol 1997;169:1139-1144.

33. Ho KY, de Haan MW, Kessels AG, Kitslaar PJ, van Engelshoven JM. Peripheralvascular tree stenoses: detection with subtracted and nonsubtracted MR angiography.Radiology1998;206:673-681.

34. Quinn SF, Sheley RC, Semonsen KG, Leonardo VJ, Kojima K, SzumowskiJ.Aortic and lower-extremity arterial disease: evaluation with MR angiography versus conventional angiography. Radiology 1998;206:693-701.

35. Nelemans PJ, Leiner T, de Vet HC, van Engelshoven JM. Peripheral arterial disease: Meta-analysis of the diagnostic performance of MR angiography. Radiology 2000;217:105-114.

36. Koelemay MJ, Lijmer JG, Stoker J, Legemate DA, Bossuyt PM. Magnetic resonance angiography for the evaluation of lower extremity arterial disease: A meta-analysis. JAMA 2001;285:13381345.

37. Ouwendijk R, de Vries M, Stijnen T, Pattynama PM, van Sambeek MR, ButhJ,et al. Multicenter randomized controlled trial of the costs and effects of noninvasive diagnostic imaging in patients with peripheral arterial disease: the DIPAD trial. AJR Am J Roentgenol 2008;190:1349-1357.

38. Hingorani A, Ascher E, Marks N. Preprocedural imaging: New options to reduceneed for contrast angiography. SeminVascSurg 2007;20:15-28.

39. Astrup A, Dyerberg J, Elwood P, Hermansen K, Hu FB, Jakobsen MU, et al. The role of reducing intakes of saturated fat in the prevention of cardiovascular disease: Where does the evidence stand in 2010? Am J Clin Nutr 2011;93:684-688.

40. He K, Song Y, Daviglus ML, Liu K, Van Horn L, Dyer AR, Greenland $P$. Accumulated evidence on fish consumption and coronary heart disease mortality: A meta-analysis of cohort studies. Circulation 2004;109:2705-2711.

41. Mozaffarian D, Katan MB, Ascherio A, Stampfer MJ, Willett WC Trans fatty acids and cardiovascular disease. $N$ Engl J Med 2006;354:1601-1613.

42. Dauchet L, Amouyel P, Hercberg S, Dallongeville J. Fruit and vegetable consumption and risk of coronary heart disease: a metaanalysis of cohort studies. J Nutr 2006;136:2588-2593.

43. He FJ, Nowson CA, MacGregor GA. Fruit and vegetable consumption and stroke: Meta-analysis of cohort studies. Lancet 2006;367:320-326. 
44. Corrao G, Bagnardi V, Zambon A, La Vecchia C. A meta-analysis of alcohol consumption and the risk of 15 diseases. Prev Med 2004;38:613-619.

45. Sofi F, Abbate R, Gensini GF, Casini A. Accruing evidence on benefits of adherence to the Mediterranean diet on health: an updated systematic review and meta-analysis. Am J Clin Nutr 2010;92:11891196.

46. Taylor RS, Brown A, Ebrahim S, Jolliffe J, Noorani H, Rees K, et al. Exercise-based rehabilitation for patients with coronary heart disease: Systematic review and meta-analysis of randomized controlled trials. Am J Med 2004;116:682-692.

47. Piepoli MF, Davos C, Francis DP, Coats AJ. Exercise training metaanalysis of trials in patients with chronic heart failure (ExTraMATCH). BMJ 2004;328:189.

48. Whitlock G, Lewington S, Sherliker P, Clarke R, Emberson J, Halsey J, et al. Body-mass index and cause-specific mortality in 900000 adults: Collaborative analyses of 57 prospective studies. Lancet 2009;373:1083-1096.

49. Berrington de Gonzalez A, Hartge P, Cerhan JR, Flint AJ, Hannan L, MacInnis RJ, et al. Body-mass index and mortality among 1.46 million white adults. N Engl J Med 2010;363:2211-2219.

50. Zheng W, McLerran DF, Rolland B, Zhang X, Inoue M, Matsuo K, et al. Association between body-mass index and risk of death in more than 1 million Asians. N Engl J Med 2011;364:719-729.

51. Steinberg MB, Greenhaus S, Schmelzer AC, Bover MT, Foulds J, Hoover DR, Carson JL. Triple-combination pharmacotherapy for medically ill smokers: a randomized trial. Ann Intern Med 2009;150:447-454.

52. Momsen AH, Jensen MB, Norager CB, Madsen MR, VestersgaardAndersen T,Lindholt JS. Drug therapy for improving walking distance in intermittent claudication:A systematic review and metaanalysis of robust randomized controlled studies. Eur J VascEndovasc Surg 2009;38:463-474.

53. Yusuf S, Sleight P, Pogue J, Bosch J, Davies R, Dagenais G. Effects of an angiotensin-converting-enzyme inhibitor, ramipril, on cardiovascular events in high-risk patients. The Heart Outcomes Prevention Evaluation Study Investigators. NEngl J Med 2000;342:145-153.

54. Yusuf S, Teo KK, Pogue J, Dyal L, Copland I, Schumacher H, Dagenais G,Sleight P, Anderson C. Telmisartan, ramipril, or both in patients at high riskf or vascular events. N Engl J Med 2008;358:15471559.

55. Baigent C, Blackwell L, Collins R, Emberson J, Godwin J, Peto R, et al. Aspirin in the primary and secondary prevention of vascular disease: Collaborative meta-analysis of individual participant data from randomised trials. Lancet 2009;373:1849-1860.

56. A randomised, blinded, trial of clopidogrel versus aspirin in patients at risk of ischaemic events (CAPRIE). CAPRIE Steering Committee. Lancet 1996;348:1329-1339.

57. Bhatt DL, Fox KA, Hacke W, Berger PB, Black HR, Boden WE, et al. Clopidogrel and aspirin versus aspirin alone for the prevention of atherothrombotic events. NEngl J Med 2006;354:1706-1717.

58. Cacoub PP, Bhatt DL, Steg PG, Topol EJ, Creager MA. Patients with peripheral arterial disease in the CHARISMA trial. Eur Heart J 2009;30:192-201.

59. Hobbs SD, Bradbury AW. Smoking cessation strategies in patients with peripheral arterial disease: An evidence-based approach. Eur J Vasc Endovasc Surg 2003;26:341-347.

60. Mancia G, De Backer G, Dominiczak A, Cifkova R, Fagard R, GermanoG,et al., The taskforce for the management of arterial hypertension of the European Society of Hypertension, The task force for the management of arterial hypertension of the European Society of Cardiology. 2007 Guidelines for the management of arterial hypertension: The Task Force for the Management of Arterial Hypertension of the European Society of Hypertension (ESH) and of the European Society of Cardiology (ESC). Eur Heart J 2007;28:14621536.

61. Aronow WS, Ahn C. Effect of beta blockers on incidence of new coronary events in older persons with prior myocardial infarction and symptomatic peripheral arterial disease. Am J Cardiol 2001;87:1284-1286.
62. Poldermans D, Bax JJ, Boersma E, De Hert S, Eeckhout E, Fowkes G, et al. Guidelines for preoperativecardiac risk assessment and perioperative cardiac management in noncardiacsurgery: the Task Force for Preoperative Cardiac Risk Assessment and Perioperative Cardiac Management in Non-cardiac Surgery of the EuropeanSociety of Cardiology (ESC) and European Society of Anaesthesiology (ESA).Eur Heart J 2009;30:2769-2812.

63. Claeys R, Bogaert M, Clement D. Study on the non-drug, conservative treatment of intermittent claudication. T Geneeskunde 1982;38:585588.

64. O'Donnell ME, Badger SA, Sharif MA, Young IS, Lee B, Soong CV. The vascular and biochemical effects of cilostazol in patients with peripheral arterial disease. J Vasc Surg 2009;49:1226-1234.

65. Twine CP, McLain AD. Graft type for femoro-popliteal bypass surgery. Cochrane Database Syst Rev 2010;5:CD001487.

66. Diehm N, Schillinger M, Minar E, Gretener S, Baumgartner I. TASC II section E3on the treatment of acute limb ischemia: commentary from European interventionists. J Endovasc Ther 2008;15:126-128.

67. Brown J, Lethaby A, Maxwell H, Wawrzyniak AJ, Prins MH Antiplatelet agents for preventing thrombosis after peripheral arterial bypass surgery. Cochrane Database Syst Rev 2008;4:CD000535.

68. Efficacy of oral anticoagulants compared with aspirin after infrainguinal bypass surgery (The Dutch Bypass Oral Anticoagulants or Aspirin Study): A randomized trial. Lancet 2000;355:346-351.

69. Belch JJ, Dormandy J, CASPAR Writing Committee, Biasi BM, CairolsM,Diehm C, Eikelboom B, et al. Results of the randomized,placebo-controlled clopidogrel and acetylsalicylic acid in bypass surgery for peripheral arterial disease (CASPAR) trial. J Vasc Surg 2010;52:825-833, 833 e821-822. 